\title{
Correction to: Belongingness is a Mediating Factor Between Religious Service Attendance and Reduced Psychological Distress During the COVID-19 Pandemic
}

\author{
Jay L. Michaels ${ }^{1}\left(\mathbb{D} \cdot\right.$ Feng Hao $^{2} \cdot$ Nicole Ritenour $^{1} \cdot$ Naomi Aguilar $^{1}$
}

Published online: 9 February 2022

(C) Springer Science+Business Media, LLC, part of Springer Nature 2022

\section{Correction to: Journal of Religion and Health: https://doi.org/10.1007/s10943-021-01482-5}

In this article, the affiliation details for the second author "Feng Hao" were incorrectly provided as "Department of Psychology, University of South Florida." The correct affiliation is "Department of Sociology, University of South Florida." This has been corrected with this erratum.

Publisher's Note Springer Nature remains neutral with regard to jurisdictional claims in published maps and institutional affiliations.

The original article can be found online at https://doi.org/10.1007/s10943-021-01482-5.

Jay L. Michaels

jaymichaels@usf.edu

1 Department of Psychology, University of South Florida Sarasota-Manatee, 8350 N. Tamiami Trail, Sarasota, FL 34243, USA

2 Department of Sociology, University of South Florida Sarasota-Manatee, 8350 N. Tamiami Trail, Sarasota, FL 34243, USA 